This is an Open Access article licensed under the terms of the Creative Commons AttributionNonCommercial-NoDerivs 3.0 License (www.karger.com/OA-license), applicable to the online version of the article only. Distribution for non-commercial purposes only.

Review

\title{
Sphingosine 1-Phosphate in Renal Diseases
}

\author{
Alexander Koch ${ }^{\mathrm{a}}$ Josef Pfeilschifter ${ }^{\mathrm{a}} \quad$ Andrea Huwiler $^{\mathrm{b}}$ \\ aPharmazentrum Frankfurt/ZAFES, Klinikum der Johann Wolfgang Goethe-Universität, \\ Frankfurt am Main; 'bnstitute of Pharmacology, University of Bern, Bern
}

\section{Key Words}

Sphingosine 1-phosphate - Kidney disease - Diabetic nephropathy • Glomerulonephritis • Ischemia-reperfusion injury $\cdot$ Wilms tumor

\begin{abstract}
Because of its highly bioactive properties sphingosine 1-phosphate (S1P) is an attractive target for the treatment of several diseases. Since the expression of sphingosine kinases as well as S1P receptors was demonstrated in the kidney, questions about the physiological and pathophysiological functions of S1P in this organ have been raised. In this review, we summarize the current state of knowledge about S1P-mediated functions in the kidney. A special focus is put on S1P modulated signal transduction in renal glomerular and tubular cells and consequences for the development and treatment of several kidney diseases, diabetic nephropathy, glomerulonephritis, ischemia-reperfusion injury, as well as for Wilms tumor progression.
\end{abstract}

Copyright (C) 2013 S. Karger AG, Basel

\section{Introduction}

The sphingolipid molecule sphingosine 1-phosphate (S1P) was first reported as signaling molecule by Ghosh et al. [1] who proposed that sphingosine is intracellularly converted to S1P, which in turn triggers an enhanced calcium mobilization from a calcium pool including an inositol trisphosphate sensitive pool. In parallel, the group of Sarah Spiegel showed that exogenously added sphingosine is able to enhance proliferation of Swiss 3T3 fibroblasts [2] which was later specified to be due to the intracellular conversion of sphingosine to S1P [3]. Indeed, a sphingosine kinase (SK) activity had already been characterized many years 
before in blood platelets [4]. To date, two subtypes of SK, SK-1 and SK-2, and several splice variants of each subtype, have been cloned and partially characterized (reviewed in [5]). These subtypes are ubiquitously expressed but show differential biochemical properties and subcellular localizations. Therefore, it is very likely that S1P generated by the two enzymes at different subcellular sites may exert different cellular functions. S1P mainly acts as an extracellular ligand for specific cell surface receptors, the S1P receptors (S1PRs), which belong to the superfamily of G protein-coupled receptors. Five subtypes of these receptors have been identified, denoted $\mathrm{S}_{1} \mathrm{P}_{1-5}$, which trigger various cell responses depending on the cell type, including proliferation, migration and survival. Moreover, several intracellular targets for S1P were recently identified, indicating novel modes of action for this lipid second messenger $[6,7]$. Because of its highly bioactive properties S1P is an attractive target for the treatment of several diseases. Since the expression of SKs as well as S1PRs was demonstrated in kidney lysates as well as in isolated renal cells [8-13], questions about the physiological and pathophysiological functions of S1P in this organ have been raised. Here, we summarize the current state of knowledge about S1P-mediated functions in the kidney. A special focus is put on S1P modulated signal transduction in renal cells and consequences for the development and treatment of several kidney diseases as well as for renal tumor progression.

\section{S1P in renal cells}

In the last years, much effort has been undertaken to unravel the cellular functions of S1P in renal cells. Most of these studies have focused on cells isolated from renal glomeruli, including glomerular visceral epithelial cells (podocytes), mesangial cells (MC) and glomerular endothelial cells (Fig. 1), which play important roles in the pathogenesis of several renal diseases including diabetic nephropathy (DN) and various forms of glomerulonephritis (GN). Other studies have focused on the effect of S1P on tubular cells which are thought to be critically involved in the pathogenesis of renal ischemia-reperfusion-induced injury (IRI).

\section{Glomerular cells}

Glomerular MC are smooth muscle-like cells located in the intercapillary space of the glomerulus. Physiologically, they participate in the regulation of the glomerular filtration as well as in the preservation of structural integrity of the glomerulus (reviewed in [1416]). In addition, in many forms of glomerular diseases $M C$ are activated and show altered migration and proliferation, increased production of extracellular matrix (ECM) components and inflammatory mediators (reviewed in [15-17]). Chen et al. [18] first demonstrated that in cultures of rat MC, S1P as well as sphingosylphosphorylcholine act as exogenous stimuli to trigger increased calcium mobilization and arachidonic acid release through phospholipase C activation. Subsequently, Gennero et al. [11] reported that S1P can either increase proliferation of $\mathrm{MC}$ in culture or induce cell death depending on the cell density of the cultures. These authors also characterized for the first time the S1PR expression profile in rat mesangial cells which included the $\mathrm{S}_{1} \mathrm{P}_{1-3,}$ and $\mathrm{S}_{1} \mathrm{P}_{5}[11]$. The proliferative capacity of exogenous S1P on MC was confirmed by Hanafusa et al. [19]. These authors also showed that $\mathrm{S} 1 \mathrm{P}$ is neither formed nor released upon cell stimulation with platelet-derived growth factor (PDGF), which is normally secreted from platelets present in damaged or inflamed glomeruli [20]. However, other studies clearly revealed a cross-communication between PDGF and $\mathrm{S} 1 \mathrm{P}$ signaling in MC proliferation. Katsuma et al. [10] showed that PDGF up-regulated S1P expression. Furthermore, they suggested the specific involvement of $\mathrm{S}_{1} \mathrm{P}_{2}$ and $\mathrm{S}_{1} \mathrm{P}_{3}$ in $\mathrm{MC}$ proliferation. Both receptor subtypes were shown to couple through a pertussis toxin (PTX)sensitive G protein that resulted in the activation of the classical mitogen activated protein kinase/extracellular signaling regulated kinase (MAPK/ERK) pathway. A connection between PDGF and S1P was also forwarded by Olivera and Spiegel [21] who showed that PDGF can activate SK-1 and induce a nuclear translocation of the enzyme [22]. In this context, S1P was 
Fig. 1. Cellular and structural components of a renal glomerulus. The immunohistochemical staining (right panel) was generated using a kidney paraffin section stained with periodic acid-Schiff reagent. Counterstaining was performed using Mayer`s Hemalaun.



postulated as an intracellular second messenger mediating PDGF-induced proliferation of mouse fibroblasts [21]. Also, Katsuma et al. [10] showed that PDGF induced SK expression and activity as well as intracellular S1P formation in rat MC, leading to the conclusion that SK is at least in part involved in PDGF-induced MC proliferation. Altogether, these studies clearly established a prominent role of the SK/S1P pathway in MC proliferation.

In addition to the proliferative effect, S1P is well known to trigger cell survival. In this context, Hofmann et al. [13] investigated the role of the two SK isoforms, SK-1 and SK-2, in staurosporine induced apoptosis. They showed that renal MCs isolated from SK-2 knockout mice were resistant to staurosporine-induced apoptosis whereas the absence of SK-1 led to a more pronounced apoptotic response to staurosporine. These data suggested an opposite function of SK-1 and SK-2 on apoptotic cell responses and were in line with the previous report by Liu et al. [23] who showed that SK-2 is a pro-apoptotic enzyme, which through its $\mathrm{BH} 3$ domain binds and traps the anti-apoptotic Bcl-2-family member Bcl- $\mathrm{X}_{\mathrm{L}}$. Additionally, Igarashi et al. [24] demonstrated that SK-2 is a nuclear protein which inhibits DNA synthesis in various cell lines. In contrast to the poorly understood functions of SK-2 on cell growth and death, the anti-apoptotic function of SK-1 has been more extensively studied and various reports confirmed this hypothesis. In this regards, it was recently shown that certain nephroprotective drugs such as glucocorticoids [25] or PPAR $\gamma$ agonists [26] act at least partially by up-regulating SK-1 expression and activity and consequently increase the cellular S1P level in MC which in turn mediates protection from either stress-induced cell death [25] or fibrotic reactions [26].

An effect of S1P on cell migration of various cell types is also well established. This observation may have impact not only on cancer cell growth, progression and metastasis, but also for renal diseases where migration of MCs is a typical feature like in the early phase of mesangioproliferative glomerulonephritis. Depending on the S1PR subtype expression pattern in different cell types, exogenous $\mathrm{S} 1 \mathrm{P}$ can either stimulate (via $\mathrm{S}_{\mathrm{P}} \mathrm{P}_{1}$ or $\mathrm{S}_{1} \mathrm{P}_{3}$ ) or inhibit (via $\mathrm{S}_{1} \mathrm{P}_{2}$ ) migration (reviewed in [27]). In renal MC cultures, it was demonstrated that extracellular S1P, but also the extracellular nucleotides ATP and UTP which act through P2Y purinoceptors, can stimulate MC migration [12]. Down-regulation of SK-1 by siRNA transfection of $\mathrm{MC}$, abrogated the migratory response induced by the nucleotides and remarkably also by S1P [12] suggesting that SK-1 is a key enzyme mediating migration by various extracellular stimuli including S1P itself. This also agrees with the data by Meyer zu Heringdorf et al. [28] who showed that activation of S1PRs enhance SK-1 activity in human embryonic kidney cells (HEK293). These authors speculated that the cells may respond to SK-1 up-regulation/activation by an up- or down-regulation of certain S1PR subtypes. 
We recently forwarded the concept that extracellular S1P (eS1P) and intracellular S1P (iS1P) could have opposite effects on certain cell responses such as a fibrotic response. The pro-fibrotic marker connective tissue growth factor (CTGF) is well known to be up-regulated and secreted by transforming growth factor $\beta$ (TGF- $\beta$ ) in vitro and in vivo in the course of fibrotic events that are common endpoints of nearly all chronic kidney diseases. The first hint that eS1P affected the pro-fibrotic CTGF came from cDNA microarray analyses of S1P and dihydro-S1P stimulated MC that showed an up-regulation of CTGF mRNA expression by S1P and dihydro-S1P [29]. Later on, Xin et al. [30] demonstrated that also CTGF protein expression and secretion is enhanced by eS1P and forwarded a novel crosstalk activated by S1P and its receptors and the TGF- $\beta /$ Smad signaling pathway. Thus, via one of the S1PRs S1P cross-activated the TGF- $\beta$ receptor complex and thereby acted as a TGF- $\beta$ mimetic in renal MC. A similar mechanism of S1P-triggered Smad activation was later also observed in keratinocytes [31] and in the murine Langerhans cell line XS52 [32]. Furthermore, the mechanism of CTGF up-regulation by S1P seemed not to be restricted to MC, but also occurred in cells of epithelial origin such as in podocytes [33]. In addition, Xin et al. [34] demonstrated that FTY720 and phospho-FTY720 were able to induce CTGF expression in renal MCs via cross-activation of the Smad signaling cascade. Consistent with previously published effects of S1P [30], FTY720 and its derivative phospho-FTY720 induced Smad phosphorylation in a PTX insensitive but suramin dependent manner. Suramin was reported as a selective $\mathrm{S}_{1} \mathrm{P}_{3}$ antagonist when compared to the other S1PR subtypes [35] which made it temping to suggest that the $\mathrm{S}_{1} \mathrm{P}_{3}$ would be involved in the S1P- and FTY720-triggered Smad cross-activation and subsequent CTGF expression [30, 34]. However, suramin is a rather unspecific drug and many other G protein-coupled receptors were shown to be affected by suramin as well. Therefore, it remains unclear whether $\mathrm{S}_{1} \mathrm{P}_{3}$ is indeed involved in the fibrotic response in renal MC. In this context, Katsuma et al. [36] suggested that $\mathrm{S}_{2} \mathrm{P}_{2}$ and/or $\mathrm{S}_{3} \mathrm{P}_{3}$, are involved in the S1P-induced CTGF expression in renal MCs. More recent data in tumor cells rather suggested the $\mathrm{S}_{1} \mathrm{P}_{2}$ to be involved in the pro-fibrotic effects of eS1P [37]. This conclusion is derived from the finding that phospho-FTY720, which cannot bind to the $\mathrm{S1P}_{2}$ [38], had no effect on CTGF expression in the Wilms' tumor cell line WiT49 ([37], see below). Furthermore, the $\mathrm{S}_{1} \mathrm{P}_{2}$ antagonist JTE-013 completely blocked the S1P-induced CTGF expression in these cells, whereas the $\mathrm{S}_{1} \mathrm{P}_{1}$ antagonist VPC-44116 did not.

The pro-fibrotic potential of eS1P measured by the up-regulation of CTGF protein expression and secretion was also confirmed for human podocytes [33]. These authors also investigated the role of SK-1 in the expression of CTGF in human podocytes. Interestingly, they could show that the pro-fibrotic cytokine TGF- $\beta$ strongly up-regulated the protein expression and activity of SK-1. Strikingly, this SK-1 activation and generation of iS1P attenuated CTGF expression in podocytes, thus, iS1P rather acted anti-fibrotic. These results were further corroborated by the use of caged S1P which is an inactive S1P derivative that is readily taken up by cells and upon photolysis is cleaved into mature S1P [39]. Caged S1P, when applied to cells and photolysed to generate iS1P, also attenuated CTGF expression [33]. In addition, SK-1 overexpression expected to generate high amounts of iS1P also reduced CTGF expression in the supernatant, whereas a pharmacological inhibitor of SK-1, SKI II (2-(p-hydroxyanilino)-4-(p-chlorophenyl) thiazole), led to a more pronounced CTGF expression upon TGF- $\beta$ treatment. These findings in podocytes were recently also confirmed for MC [26]. These authors demonstrated that thiazolidinediones (TZDs) which are agonists of the peroxisome proliferator-activated receptor gamma, also induce SK-1 expression and activity and the generation of iS1P in renal MC, which was functionally coupled to lower amounts of CTGF. Pharmacological and genetic approaches to inhibit SK-1 abolished this effect in vivo and in vitro, suggesting that the known anti-fibrotic potential of TZDs is at least partially due to iS1P generation [26]. All these data strongly suggest that targeting of eS1P is a valid approach to prevent fibrotic processes. Alternatively, one may stimulate intracellular SK-1 activity and increase the levels of iS1P. However, this is a double edged sword since iS1P could as well be secreted by still unclear mechanisms and once in the extracellular space it may turn into a pro-fibrotic signal (Fig. 2). 


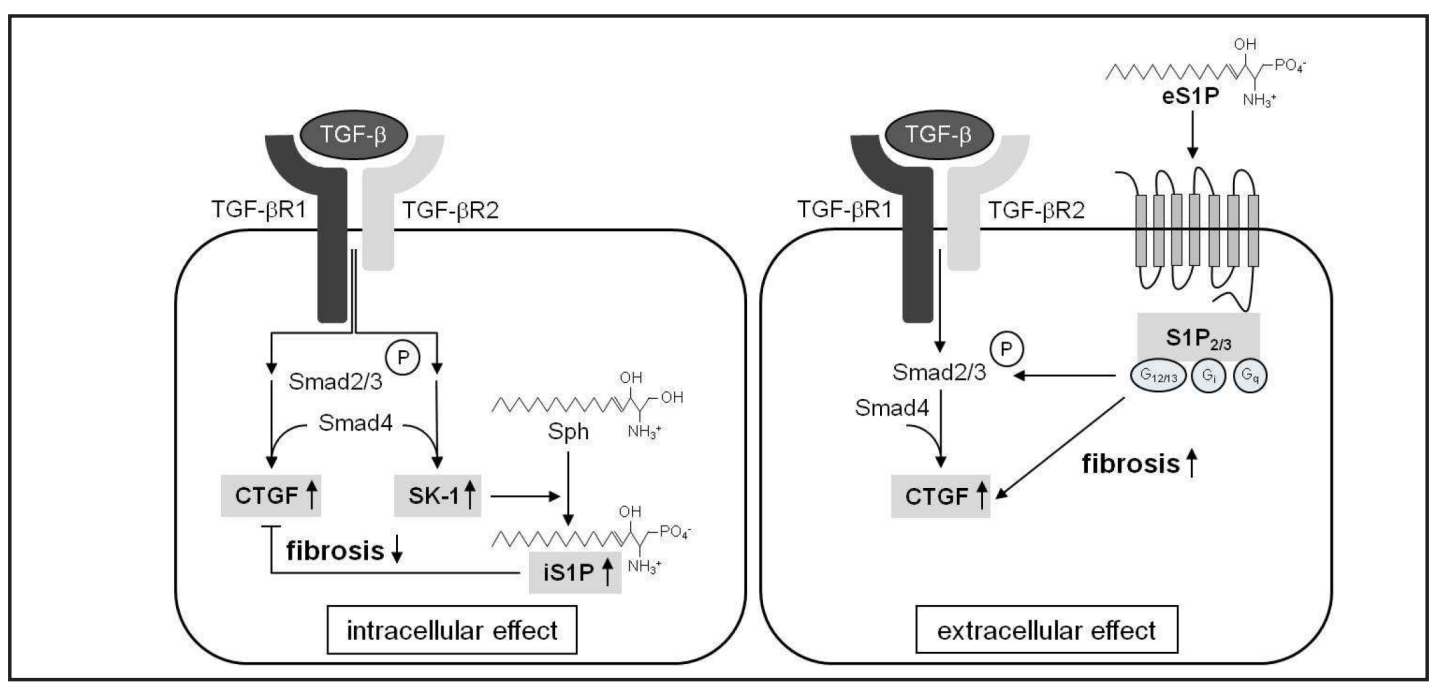

Fig. 2. Schematic overview on the opposite effects of intracellular (left panel) and extracellular (right panel) S1P for the expression of pro-fibrotic CTGF in renal glomerular cells. Abbreviations used: CTGF, connective tissue growth factor; S1P, sphingosine-1-phosphate; S1PR, S1P receptor; SK-1, sphingosine kinase 1; Sph, sphingosine; TGF- $\beta$, transforming growth factor $\beta$; TGF- $\beta$ R, TGF- $\beta$ receptor.

Lan et al. [40] reported the up-regulation of SK-1 under high glucose conditions which was paralleled by increased iS1P levels and fibronectin expression in MCs. Surprisingly, SK-1 siRNA and the SK inhibitor $N, N$-dimethylsphingosine (DMS) abolished the high glucoseinduced fibronectin expression, proposing a rather pro-fibrotic role of SK-1. By the use of the $\mathrm{S}_{1} \mathrm{P}_{2}$ antagonist JTE-013 the authors further suggested that $\mathrm{S}_{2} \mathrm{P}_{2}$ is involved in this profibrotic response [40], in line with various previous studies highlighting the pro-fibrotic contribution of eS1P and $\mathrm{S}_{2} \mathrm{P}_{2}$.

\section{Tubular cells}

Among a wide range of tubular cell lines available, the human HK-2 cell line and the mouse TKPTS proximal tubular cell line are the most widely used cell culture models for current studies to unravel the regulatory function of S1P in IRI based molecular events. The proximal tubule is highly oxygenated under healthy conditions and is associated with a high metabolic rate $[41,42]$. Proximal tubular cells represent the primary site of damage upon ischemia/reperfusion and therefore, these cells are considered a suitable model system to study in vitro the molecular details of IRI. Immortalized HK-2 cells were derived from normal adult human kidney proximal tubular epithelium by transduction with human papilloma virus 16 E6/E7 [43]. Using this HK-2 cell line, Kim et al. [44] demonstrated that the anesthetic drug isoflurane induced SK-1 mRNA expression as well as SK-1 activity which resulted in increased S1P generation. They also found that in vivo in a murine model of IRI, isoflurane protected from renal failure and necrosis and that the protection was lost by SK inhibitor treatment and by a $\mathrm{S}_{1 / 3}$ antagonist ([44], see below). The protective and anti-necrotic mechanism in HK-2 cells was suggested to include $\mathrm{S}_{1} \mathrm{P}_{1}$-mediated ERK and protein kinase $\mathrm{B} /$ Akt activation and heat shock protein 70 induction [45] as well as release of TGF- $\beta 1$ [46]. They put forward the hypothesis that an interaction between isoflurane and plasma membranes and particularly caveolar microdomains would lead to TGF- $\beta 1$ release, which in turn stimulates SK-1 and S1P formation with a subsequent $\mathrm{S}_{1} \mathrm{P}_{1}$ activation to ERK stimulation [47]. A novel therapeutic application for inhalational anesthetics was thus suggested by the authors. A similar protective effect of $\mathrm{S}_{1} \mathrm{P}_{1}$ activation was also reported for the mouse TKPTS cell line [48]. Additionally, overexpression of SK-1 in HK-2 cells also protected against peroxide-induced necrosis and led to enhanced heat shock protein 27 expression that was reversed by $\mathrm{S}_{1} \mathrm{P}_{1}$ antagonism [49]. Finally, Park et al. [50] showed 
that the selective $\mathrm{S}_{1} \mathrm{P}_{2}$ antagonist JTE-013 induced SK-1 expression and further attenuated necrosis and apoptosis in HK-2 cells, whereas a $\mathrm{S}_{2} \mathrm{P}_{2}$ agonist had the opposite effect. Indeed, the finding that a receptor antagonist in the absence of the receptor ligand has gene inducing capability is surprising at a first glance and it can presently not be excluded that JTE-013 may have additional cellular effects, e.g. acting as a partial agonist or even unspecifically.

Altogether, these in vitro data further established the protective function of S1P in an increasing number of cellular systems.

\section{S1P in renal disease models}

First evidence for the importance of S1P in renal physiology was given by Bischoff et al. [51-53] who showed that intravenous and intrarenal infusions of S1P led to renal vasoconstriction and caused natriuresis in spite of a reduction of renal blood flow ([5153], reviewed in [54]). The effects were blocked by PTX indicating the involvement of at least one $\mathrm{G}_{i}$-coupled S1PR [52]. More than one decade later, Zhu et al. [55] readdressed the involvement of S1PR subtypes in renal function. They demonstrated that intramedullary administration of FTY720 produced an increase in sodium excretion, an effect which was blocked with the $\mathrm{S}^{\mathrm{P}}{ }_{1}$ antagonist W146. Consequently, the authors suggested that S1P might produce natriuretic effects via activation of $\mathrm{S}_{1} \mathrm{P}_{1}$, which in turn affects transport mechanisms in the renal medulla [55]. The understanding of S1P signaling in many cellular systems promotes the idea to use this knowledge to treat diverse diseases. To date, various strategies are discussed to either specifically activate or inhibit S1PRs or to deplete S1P from the serum/plasma and thereby to diminish its pathophysiological actions. The usefulness of eliminating plasma S1P levels in the treatment of angiogenic diseases was recently proven by using a neutralizing anti-S1P antibody (sonepcizumab ${ }^{\circledR}$ ). Humanized S1P antibodies were effective in blocking S1P-mediated release of pro-angiogenic and prometastatic cytokines in cancer models $[56,57]$ and also reduced injury in a laser-induced retinopathy model [58]. A different approach was recently forwarded by Huwiler et al. [59] who used recombinant S1P lyase from a thermostable bacterium (Symbiobacterium thermophilum). This prokaryotic enzyme, in contrast to the eukaryotic enzyme, lacks a transmembrane sequence at its $\mathrm{N}$-terminus and therefore lacks membrane association. Intravenous application of this S1P lyase rapidly degraded plasma S1P levels but the effect was only transient and after $6 \mathrm{~h}$, plasma S1P had recovered to normal levels again [59]. When used in a neovascularization model of the developing chicken embryo, the chorioallantoic membrane (CAM) model, recombinant Symbiobacterium thermophilum S1P lyase significantly reduced vessel formation triggered by injected tumor cells [59].

Numerous studies not only addressed the function of S1P in renal cells but also in diverse in vivo diseases models. In the following part, we will recapitulate the present data generated in situations of DN, GN and IRI.

\section{Diabetic nephropathy}

Nearly $30 \%$ of all diabetic patients develop DN, the major cause of end-stage renal failure, which is characterized by clinical symptoms like albuminuria and declined glomerular filtration rate. Pathological hallmarks of DN are enhanced secretion and deposition of ECM proteins, the expansion of the mesangium and the thickening of the glomerular basement membrane (reviewed in [60]). The enhanced secretion of cytokines and growth factors (e.g. TGF- $\beta$, CTGF) and subsequent MC proliferation and ECM accumulation lead to substantial fibrotic changes in the kidney and to the initiation of glomerulosclerosis.

Based on the in vitro findings described above, several groups investigated how sphingolipid metabolism is altered under diabetic conditions in vivo. A variety of diabetic mouse models are available which however show substantial differences in the renal consequences of diabetes (reviewed in [61]). The application of a single high dose of streptozotocin (STZ) is a widely used and well-established murine model for DN. Its diabetes 
inducing effect is based on the toxicity of STZ on pancreatic $\beta$-cells and it thereby mimics specifically type 1 diabetes. Using this STZ model in rats, Geoffroy et al. [62] showed that neutral ceramidase and SK activities were significantly up-regulated in isolated glomeruli from 4 days STZ treated rats. They also determined increased S1P levels in the glomeruli although the sphingosine levels were not altered. Derived from these observations, they suggested a possible involvement of sphingolipid metabolites in the glomerular proliferative response in the early stage of DN [62]. In line with this notion, Lan et al. [63] showed that substances that ameliorated alloxan-induced DN in mice such as berberine, also downregulated SK-1 mRNA and protein expression and S1P levels in vivo. Although they did not show a causal link between the SK-1 down-regulation and disease amelioration, they proposed that inhibition of SK1/S1P may be a new therapeutic option for renoprotection in diabetes. The same group recently published that the up-regulation of SK-1 in STZ induced DN in mice was paralleled by enhanced levels of the matrix constituent fibronectin [40]. Further mechanistic studies however were only performed in MC cultures where the authors showed that SK-1 down-regulation or inhibition, or alternative stimulation with exogenous S1P, resulted in reduced fibronectin production. In another study, Ren et al. [33] also demonstrated the up-regulation of SK-1 in STZ-induced DN, but these authors by contrast suggested the up-regulation of SK-1 to be a protective mechanism in the fibrotic process. When using SK-1 knockout mice, they found a more severe STZ-induced disease as measured by higher albuminuria and enhanced CTGF expression in kidney sections when compared to wild type C57BL/ 6 mice [33]. The mechanism was further investigated in cultures of human podocytes where they could show that TGF- $\beta$ is not only a strong inducer of fibrogenic CTGF, but remarkably also of SK-1. Inhibiting SK-1 by an inhibitor, SKI II, or down-regulating SK-1 by siRNA, led to an amplified CTGF expression, whereas overexpression of SK-1 or using cagedS1P to increase iS1P resulted in reduced CTGF expression. Collectively, these data strongly suggested that the TGF- $\beta$ dependent induction of SK-1 acts like a break in the fibrotic process by impeding CTGF expression [33]. Most critical seemed to be the site of action of S1P, either intracellularly to promote an anti-fibrotic effect, or extracellularly to trigger a pro-fibrotic response [30, 33] (Fig. 2).

However, the S1PR subtype involved in this pro-fibrotic eS1P action is still unclear. By using receptor antagonists both, the $\mathrm{S}_{1} \mathrm{P}_{2}$ and $\mathrm{S} 1 \mathrm{P}_{3}$ have been forwarded as candidates $([30,40]$, see above). In a recent study, Imasawa et al. [64] reported an unbalanced mRNA expression profile of $\mathrm{S}_{1} \mathrm{P}_{2}$ versus $\mathrm{S}_{1} \mathrm{P}_{1}$ in diabetic glomeruli in that the ratio of $\mathrm{S}_{1} \mathrm{P}_{2} / \mathrm{S}_{1} \mathrm{P}_{1}$ was increased in renal glomeruli of rats one year after STZ injection. Considering the in vitro findings of Lan et al. [40], i.e. that S1P-stimulated fibronectin expression involves $\mathrm{S} \mathrm{P}_{2}$ in $\mathrm{MC}$ cultures, the up-regulated mRNA expression of $\mathrm{S}_{1} \mathrm{P}_{2}$ in diabetic glomeruli may well point to a contribution of this receptor subtype in the pathogenesis of DN. Beside this possible disease-promoting effect of $\mathrm{S}_{1} \mathrm{P}_{2}$, a protective effect of chronic $\mathrm{S}_{1} \mathrm{P}_{1}$ activation has been suggested. Thus, Awad et al. [65] showed that STZ-induced DN in rats was reduced by either the unselective S1PR agonist FTY720 or the selective S1P agonist SEW2871. Since SEW2871 in contrast to FTY720, did not reduce circulating lymphocytes, they suggested that the renoprotective effect occurred independent of lymphocytes. Also, the protective effect of FTY720 was still observed in $\mathrm{S} \mathrm{P}_{3}$ knockout mice excluding this receptor subtype in the renoprotective mechanism [65]. Overall, these studies indicated that at least the so far discussed receptors, $\mathrm{S}_{1} \mathrm{P}_{1}$ and $\mathrm{S}_{1} \mathrm{P}_{2}$, might be attractive targets to be further considered in the treatment of DN.

\section{Glomerulonephritis}

GN is a huge group of diverse inflammatory kidney disease that irrespective of their initial triggering cause may end in end-stage renal failure. GN is divided into several subclasses depending on the clinical disease context, the progression, acute or chronic, and the histological and immunological changes involved (reviewed in [66]). A hallmark of many forms of GN is the activation of MC leading to increased MC proliferation, inflammatory mediator synthesis and ECM production. Because of their prominent role 
in the pathogenesis of GN, cultured MCs have become an attractive model system to study the molecular mechanisms in GN. The impact of S1P on these events in vitro has been discussed above. However, to date no study addressed the role of S1P in the pathogenesis of GN in vivo. A few studies investigated the effect of the immune modulator FTY720 on the progression of experimental anti-Thy1.1-induced GN. In both acute and chronic antiThy1.1-induced GN in rats, FTY720 was shown to have a beneficial effect $[67,68]$. It not only reduced lymphocyte infiltration but also reduced proteinuria, tubulointerstitial matrix expansion, TGF- $\beta 1$ and fibronectin expression. These authors suggested that the elimination of lymphocytes from the circulation and consequently also from the kidney, is the critical protective event triggered by FTY720. However, to date, it is controversially discussed how important lymphocytes are in the pathogenesis of the different forms of GN. Along this line, Lebleu et al. [69] showed evidence that lymphocytes are dispensable for GN but required for interstitial fibrosis. Moreover, Sui et al. [70] recently published that FTY720 acts protective in the model of anti-glomerular basement membrane-induced GN in mice, which could be mediated by FTY720-dependent down-regulation of $\mathrm{S}_{1} \mathrm{P}_{1}, \mathrm{~S}_{1} \mathrm{P}_{2}$ and $\mathrm{S}_{1} \mathrm{P}_{5}$ in the spleen although the exact mechanisms remained unclear. Taken together, these studies indicate that FTY720 might be an attractive approach for the treatment of both acute and chronic GN. Moreover, Wenderfer et al. [71] showed that KRP-203, a specific agonist for $\mathrm{S}_{1} \mathrm{P}_{1}$ and $\mathrm{S}_{\mathrm{P}} \mathrm{P}_{4}$ [72], decreased kidney injury and improved survival in a model of lupus nephritis (MRL/lpr mice). Those mice spontaneously develop a systemic autoimmune disease, characterized by lymphocyte accumulation in the kidney, which in turn leads to a mesangioproliferative GN and glomerulosclerosis (reviewed in [73]). Administration of KRP-203 reduced the number of infiltrating T-cells and circulating lymphocytes and therefore attenuates renal injury [71]. Again, this study stresses the idea that activation of $\mathrm{S}_{1} \mathrm{P}_{1}$ has beneficial effects in lupus nephritis and maybe also other chronic cell-mediated autoimmune diseases.

\section{Ischemia-reperfusion injury}

RI is an inescapable event in kidney transplantation often leading to acute kidney injury (AKI), which is directly linked to prolonged hospitalization, and increased morbidity and mortality (reviewed in [74]). Overall, AKI is associated with a wide range of changes in mechanisms such as intense immune responses, coagulation, generation of oxidative stress and hypoxia, and apoptosis. Since many cell culture studies have suggested the involvement of sphingolipids in these cell responses, a contribution of these lipids also in the pathogenesis of IRI seems obvious. The catabolic and metabolic routes of these lipids as well as their signaling pathways are considered attractive targets to interfere with IRI and progression to AKI. The first evidence that sphingolipids play a role in post-ischemic acute renal injury was presented by Zager et al. [75] who showed that in mice subjected to renal ischemia, a drop in cortical sphingosine and ceramide levels occurred which either normalized again after reperfusion as seen for sphingosine or even rose to supranormal levels as detected for ceramide [76, 77]. Paradoxically, acid and neutral sphingomyelinase activities both decreased in an unremitting fashion during the ischemia/24 h-reperfusion period [77] stressing the hypothesis that ceramide not only derives from sphingomyelin but also from the de-novo synthesis pathway. Recently, Jo et al. [78] used SK-1 and SK-2 deficient mice to investigate whether the conversion of ceramide/sphingosine to S1P has an effect on renal ischemia/reperfusion injury. Theoretically, depletion of SK-1 or SK-2 should lead to increased sphingosine and eventually also ceramide levels. They found no effect of SK-1 depletion on the extent of injury, but they observed more severe injury in SK-2 deficient mice [78] leading the authors to conclude that SK-2 is a protective enzyme. Opposite to this, Park et al. [49] found enhanced IRI in SK-1 deficient mice, but reduced IRI in SK-2 deficient mice. Moreover, Kim et al. [44] used the volatile anesthetic isoflurane to activate SK-1 and generate $\mathrm{S} 1 \mathrm{P}$ that, in turn, via activation of $\mathrm{S}_{1} \mathrm{P}_{1}$ protected mice from renal failure in a murine model of IRI. In SK-1 deficient mice, no protection by isoflurane occurred any more [44]. Also, the two SK-1 inhibitors DMS and SKI II abrogated the nephroprotective effect of isoflurane $[44,49]$. The reason for the discrepancy between the results of Jo et al. [78] and Park et al. 
[49] remained unclear but could be due to differences in the experimental setup, e.g. both groups used a different model of AKI as well as mice from different sources. However, SK deficient mice were also used in a myocardial ischemia/reperfusion injury model. In this model, it was shown that both SK-1 and SK-2 deficient mice exerted a more severe myocardial injury upon ischemia/reperfusion treatment when compared to wild-type mice [79, 80]. Altogether, these studies cannot give a conclusive answer about the functions of SK-1 and SK-2 in ischemia/reperfusion injuries, and clearly more studies are needed to clarify the contribution of these enzymes in ischemic injury models. More consistent are data about an IRI protective function of the product S1P. This hypothesis was further strengthened by various studies using the immunomodulatory agent FTY720. Thus, Troncoso et al. [81] demonstrated that FTY720 prevented ischemic reperfusion damage in a rat kidney model. Since FTY720 in its active phosphorylated form is an unselective S1PR agonist, acting on $\mathrm{S}_{1} \mathrm{P}_{1}$ and $\mathrm{S}_{1} \mathrm{P}_{3-5}$, the question came up which receptor subtype would mediate this protective effect of FTY720. Awad et al. [82] showed that the protective effect of FTY720 is due to a selective $\mathrm{S}_{1} \mathrm{P}_{1}$ activation since the $\mathrm{S}_{1} \mathrm{P}_{1}$ antagonist VPC-44116 reversed the protective effect of FTY720 on mouse IRI. In addition, the $\mathrm{S}_{1} \mathrm{P}_{1}$ selective agonist SEW2871 exerted a similar protective effect as FTY720 on IRI $[82,83]$. Whether the nephroprotective effect of FTY720 is only due to the depletion of peripheral lymphocytes or due to a direct effect on kidney cells is still a matter of debate. On the one side, Awad et al. [82] suggested that FTY720 acted via lymphocyte depletion. Moreover, Lai et al. [84] reported that SEW2871 prevented $\mathrm{T}$ cell infiltration, which also has been implicated in the pathogenesis of IRI [85] by inhibiting $\mathrm{T}$ cell egress from lymphoid tissue in an early stage. In contrast to these studies, Bajwa et al. [48] showed a lymphocyte independent nephroprotective effect of FTY720. Treatment with either FTY720 or SEW2871 reduced injury in both Rag-1 knockout mice, deficient for T and B lymphocytes, as well as in wild-type mice [48]. These results fit very well with their previous observation that the $\mathrm{S}_{1} \mathrm{P}_{1}$ antagonist VPC-44116 reversed FTY720-mediated nephroprotection [82]. As described above, this lymphocyte-independent protective effect was supported by in vitro findings that $\mathrm{S}_{1} \mathrm{P}_{1}$ agonists reduce cell death of mouse kidney proximal tubule epithelial cells induced by LPS- or H/R through the involvement of the ERK and Akt pathways ([48], see above). In addition, Lee et al. [86] also showed a protective effect of the S1P and S1P ${ }_{1}$ pathway in hepatic IRI-induced AKI by preventing endothelial cell injury in mice, which was proposed to occur independent of lymphocyte homing [86]. Opposite to these studies that support the involvement of S1P ${ }_{1}$, Jo et al. [78] showed that both kidney function and the reduced vascular permeability in IRI were preserved in $\mathrm{S}_{1} \mathrm{P}_{3}^{-1-}$ mice suggesting the involvement of this receptor subtype in IRI and consequently a protective effect of $\mathrm{S} \mathrm{P}_{3}$ antagonism. Regarding the source of S1P that can contribute to the protective effect in IRI, Sola et al. [87] proposed that especially macrophages, that undergo apoptosis due to IRI, release S1P which, in turn, acts in an autocrine manner on macrophage $\mathrm{S}_{1} \mathrm{P}_{3}$ to release neutrophil gelatinase-associated lipocalin (NGAL/Lcn-2) and triggers increased proliferation of tubular epithelial cells and thereby prevents from IRI-induced cell death [87]. Besides this protective effect of macrophage $\mathrm{S}_{1} \mathrm{P}_{3}$, the authors also showed that the $\mathrm{S}_{1} \mathrm{P}_{1}$ mediates a renal protection against IRI that is independent of macrophages which is in line with several previous studies [48, 82]. Furthermore, it was shown that the $\mathrm{S}_{1} \mathrm{P}_{2}$ agonist SID46371153 exacerbated renal IRI, whereas the S1P ${ }_{2}$ antagonist JTE-013 protected against renal IRI [50]. In terms of mechanism, these authors showed that inhibition of $\mathrm{S}_{1} \mathrm{P}_{2}$ led to Rho kinase and HIF- $1 \alpha$ activation, SK-1 up-regulation, S1P generation and activation of $\mathrm{S}_{1} \mathrm{P}_{1}$ that consequently triggered renoprotection. However, caution is required when making conclusions solely based on pharmacological inhibitors such as W146 and JTE-013 since the selectivity pattern of these compounds is limited and unspecific effects cannot be excluded.

\section{S1P and Wilms tumor progression}

Wilms tumor or nephroblastoma is an embryonic cancer of the developing kidney that is considered to derive from renal stem or progenitor cells that show a failure in 
differentiation. Wilms tumor is the most prevalent renal malignant tumor in children. But fortunately, it is also one of the most treatment-responsive tumors (reviewed in [88]). Thus, several therapeutic options are available to treat Wilms tumor successfully. Since plenty of evidence exists that supports a key role for S1P in tumor growth and progression both in vitro and in vivo (reviewed in [89]), it is tempting to speculate that S1P may also play a crucial role in Wilms tumor pathogenesis. By microarray analysis of advanced Wilms tumor tissue, Zirn et al. [90] identified a series of differentially expressed genes that could play a role in disease progression. Among these genes, CTGF was found to be down-regulated in advanced Wilms tumors. Furthermore, the treatment of Wilms tumor cell lines with alltrans retinoic acid, a potential therapeutic that inhibits cell proliferation and induces cell differentiation [91], normalized CTGF expression again [92]. These data led the authors to suggest a negative regulatory role for CTGF in Wilms tumor progression. However, the generality of CTGF being a negative regulator of tumor development is not given. In this view, CTGF has also been described as tumor promoter in various cancers including acute lymphoblastic leukemia, breast, cervical, hepatocellular and pancreas cancers, but as tumor suppressor in chondrosarcoma, lung and colorectal cancers (reviewed in [93]).

Li et al. [94] showed that in the Wilms tumor cell line WiT49, S1P up-regulated CTGF expression and subsequently inhibited cell proliferation which further confirmed the negative regulatory role of CTGF on Wilms tumor growth. The S1P-triggered effect on CTGF was mediated by the $\mathrm{S}_{1} \mathrm{P}_{2}$ [94]. In addition, the overexpression of $\mathrm{S}_{1} \mathrm{P}_{2}$ reduced the S1P-stimulated migration of Wilms tumor cells [95] consistent with other studies on various other cancer cell lines that also showed a negative role of $\mathrm{S}_{1} \mathrm{P}_{2}$ in cell migration (reviewed in [27]). However, it should be kept in mind that $\mathrm{S} \mathrm{P}_{2}$ may also signal to other genes. In this context, Li et al. [96] demonstrated that in WiT49 cells, the S1P/S1P axis can also induce cyclooxygenase-2 (COX-2) expression and leads to enhanced prostaglandin $\mathrm{E}_{2}$ $\left(\mathrm{PGE}_{2}\right)$ formation. However, $\mathrm{PGE}_{2}$ is known to mediate growth and progression of various tumor types by promoting angiogenesis and inhibiting apoptosis (reviewed in [97]) and it was shown that COX-2 inhibition significantly suppressed tumor growth even in vivo in an orthotopic xenograft model of human Wilms tumors in mice [98]. Thus, whether $\mathrm{S} \mathrm{P}_{2}$ activation or inhibition is more favorable in treating Wilms tumors remains uncertain.

\section{Conclusions and future perspectives}

The discovery that S1P can act in a dual way either from the extracellular space as ligand to cell surface S1PRs, or as a second messenger in the intracellular compartments to regulate a multitude of cellular processes including cell proliferation, survival, migration and modulation of gene transcription sometimes in an opposing manner, has triggered a huge research effort to understand the molecular mechanisms of S1P action and to develop strategies to regulate intracellular and extracellular S1P levels. The availability of suitable tools like genetically modified mice, low molecular mass inhibitors and highly potent receptor agonists and antagonists with improved properties will be helpful in clarifying these processes. In the past, the development of selective S1PR subtype agonists and antagonists seemed to be most attractive. Indeed, first data display a renoprotective effect of S1PR agonists, e.g. SEW2871 (S1P $)$ and KRP-203 (S1P $\left.{ }_{1,4}\right)$, and antagonists, JTE-013 (S1P $)$, in various animal models of renal diseases such as diabetic nephropathy and glomerulonephritis (Fig. 3). In this context, especially the development and market introduction of FTY720 (fingolimod, Gilenya ${ }^{\circledR}$ ) for the treatment of multiple sclerosis has undoubtedly proven the therapeutic relevance of targeting S1PRs and has strongly boosted research on sphingolipids in various other inflammatory and proliferative diseases including kidney diseases. Beside S1PR-specific strategies, the effectiveness of S1P trapping in serum/plasma by a neutralizing anti-S1P antibody (e.g. sonepcizumab ${ }^{\circledR}$ ) or S1P degradation by the use of recombinant S1P lyase to diminish its pathophysiological actions needs to be evaluated. In addition, several 


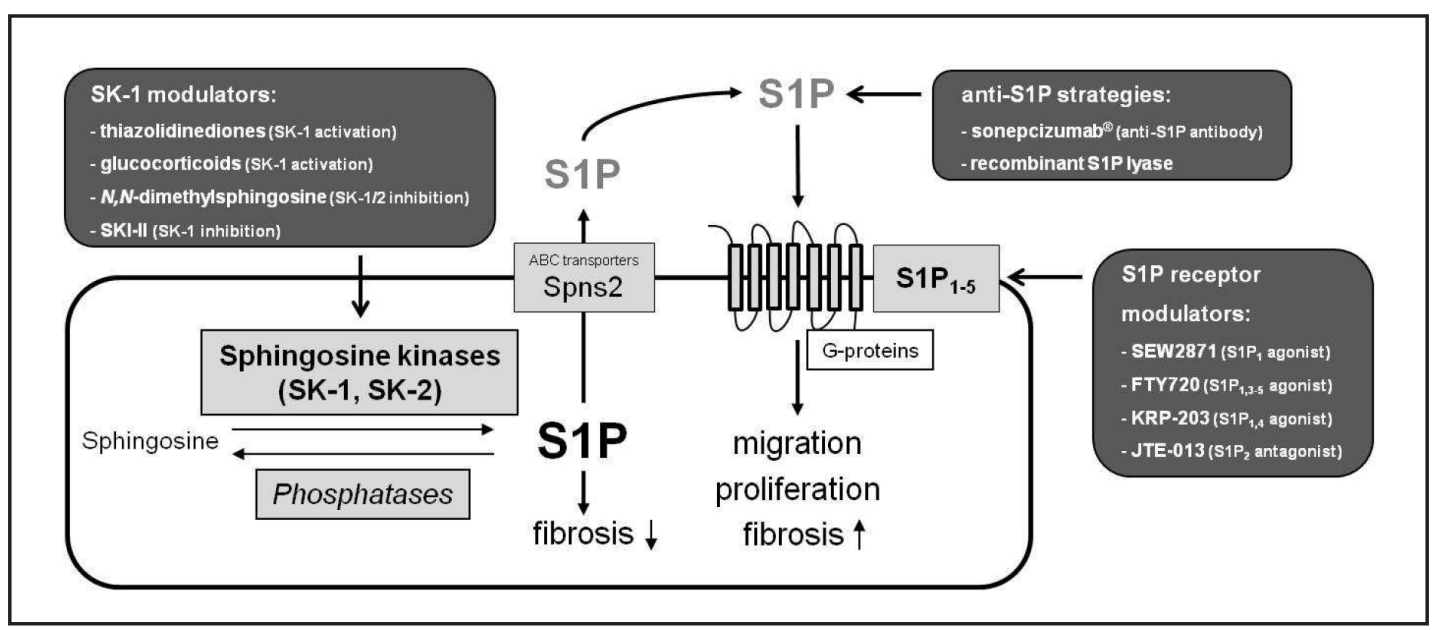

Fig. 3. Possible pharmacological interventions into sphingolipid metabolism for the treatment of renal diseases. Abbreviations used: ABC transporters; adenosine tri-phosphate binding cassette transporters; S1P, sphingosine 1-phosphate; Spns2, spinster homolog 2.

studies reveal that targeting SK-1 seems to be a worthwhile strategy to treat renal diseases (Fig. 3). However, some controversial data about the beneficial effect of either activation of SK-1 and subsequent formation of iS1P or its inhibition by SKI-II or DMS make clear that, regarding kidney diseases, the picture of S1P and its involvement in the pathogenesis of such diseases is still controversial. Therefore, the usefulness of targeting the SK/S1P/S1PR signaling device in kidney diseases awaits further clarification in future studies.

\section{Conflict of Interest}

The authors declare no conflict of interest in writing this article.

\section{Acknowledgements}

We gratefully acknowledge Anja Völzke for preparing the immunohistochemical staining. This work was supported by the German Research Foundation (FOG784, K03940/1-1, PF361/6-2, PF361/7-1, GRK1172, HU842/5-1) and the LOEWE Lipid Signaling Forschungszentrum Frankfurt and the Swiss National Science Foundation.

\section{References}

1 Ghosh TK, Bian J, Gill DL: Intracellular calcium release mediated by sphingosine derivates in cells. Science 1990;248:1653-1656.

2 Zhang H, Desai NN, Murphey JM, Spiegel S: Increases in phosphatidic acid levels accompany sphingosinestimulated proliferation of quiescent Swiss 3T3 cells. J Biol Chem 1990;65:21309-21316.

- Z Zhang H, Desai NN, Olivera A, Seki T, Brooker G, Spiegel S: Sphingosine-1-phosphate, a novel lipid, involved in cellular proliferation. J Cell Biol 1991;114:155-167.

-4 Stoffel W, Heimann G, Hellenbroich B: Sphingosine kinase in blood platelets. Hoppe Seylers Z Physiol Chem 1973;354:562-566.

5 Alemany R, van Koppen CJ, Danneberg K, Ter Braak M, Meyer Zu Heringdorf D: Regulation and functional roles of sphingosine kinases. Naunyn Schmiedebergs Arch Pharmacol 2007;374:413-428. 
Koch/Pfeilschifter/Huwiler: S1P and Kidney Diseases

6 Hait NC, Allegood J, Maceyka M, Strub GM, Harikumar KB, Singh SK, Luo C, Marmorstein R, Kordula T, Milstien S, Spiegel S: Regulation of histone acetylation in the nucleus by sphingosine-1-phosphate. Science 2009;325:1254-1257.

7 Alvarez SE, Harikumar KB, Hait NC, Allegood J, Strub GM, Kim EY, Maceyka M, Jiang H, Luo C, Kordula T, Milstien S, Spiegel S: Sphingosine-1-phosphate is a missing cofactor for the E3 ubiquitin ligase TRAF2. Nature 2010;465:1084-1088.

-8 Liu H, Sugiura M, Nava VE, Edsall LC, Kono K, Poulton S, Milstien S, Kohama T, Spiegel S: Molecular cloning and functional characterization of a novel mammalian sphingosine kinase type 2 isoform. J Biol Chem 2000;275:19513-19520.

-9 Nava VE, Lacana E, Poulton S, Liu H, Sugiura M, Kono K, Milstien S, Kohama T, Spiegel S: Functional characterization of human sphingosine kinase-1. FEBS Lett 2000;473:81-84.

10 Katsuma S, Hada Y, Ueda T, Shiojima S, Hirasawa A, Tanoue A, Takagaki K, Ohgi T, Yano J, Tsujimoto G: Signalling mechanisms in sphingosine 1-phosphate-promoted mesangial cell proliferation. Genes Cells 2002;7:1217-1230.

11 Gennero I, Fauvel J, Niéto M, Cariven C, Giats F, Briand-Mésange F, Chap H, Salles JP: Apoptotic effects of sphingosine 1-phosphate and increased sphingosine 1-phosphate hydrolysis on mesangial cells cultured at low cell density. J Biol Chem 2002;277:12724-12734.

12 Klawitter S, Hofmann LP, Pfeilschifter J, Huwiler A: Extracellular nucleotides induce migration of renal mesangial cells by upregulating sphingosine kinase-1 expression and activity. Br J Pharmacol 2007;150:271280.

13 Hofmann LP, Ren S, Schwalm S, Pfeilschifter J, Huwiler A Sphingosine kinase 1 and 2 regulate the capacity of mesangial cells to resist apoptotic stimuli in an opposing manner. Biol Chem 2008;389:1399-1407.

14 Pfeilschifter J: Cross-talk between transmembrane signalling systems: a prerequisite for the delicate regulation of glomerular haemodynamics by mesangial cells. Eur J Clin Invest 1989;19:347-361.

15 Pfeilschifter J: Mesangial cells orchestrate inflammation in the renal glomerulus. News Physiol Sci 1994;9:271-276.

16 Kerjaschki D: Caught flat-footed: podocyte damage and the molecular bases of focal glomerulosclerosis. J Clin Invest 2001;108:1583-1587.

17 Pavenstädt H, Kriz W, Kretzler M: Cell biology of the glomerular podocyte. Physiol Rev 2003;83:253-307.

18 Chen PF, Chin TY, Chueh SH: $\mathrm{Ca}^{2+}$ signaling induced by sphingosylphosphorylcholine and sphingosine 1-phosphate via distinct mechanisms in rat glomerular mesangial cells. Kidney Int 1998;54:1470-1483.

19 Hanafusa N, Yatomi Y, Yamada K, Hori Y, Nangaku M, Okuda T, Fujita T, Kurokawa K, Fukagawa M: Sphingosine 1-phosphate stimulates rat mesangial cell proliferation from outside the cells. Nephrol Dial Transplant 2002;17:580-586.

20 Yatomi Y, Yamamura S, Ruan F, Igarashi Y: Sphingosine 1-phosphate induces platelet activation through an extracellular action and shares a platelet surface receptor with lysophosphatic acid. J Biol Chem 1997;272:5291-5297.

21 Olivera A, Spiegel S: Sphingosine-1-phosphate as second messenger in cell proliferation induced by PDGF and FCS mitogens. Nature 1993;365:557-560.

-22 Kleuser B, Maceyka M, Milstien S, Spiegel S: Stimulation of nuclear sphingosine kinase activity by plateletderived growth factor. FEBS Lett 2001;503:85-90.

-23 Liu H, Toman RE, Goparaju SK, Maceyka M, Nava VE, Sankala H, Payne SG, Bektas M, Ishii I, Chun J, Milstien S, Spiegel S: Sphingosine kinase type 2 is a putative BH3-only protein that induces apoptosis. J Biol Chem 2003;278:40330-40336.

24 Igarashi N, Okada T, Hayashi S, Fujita T, Jahangeer S, Nakamura S: Sphingosine kinase 2 is a nuclear protein and inhibits DNA synthesis. J Biol Chem 2003;278:46832-46839.

-25 Förster A, Emmler T, Schwalm S, Ebadi M, Meyer zu Heringdorf D, Nieuwenhuis B, Kleuser B, Huwiler A, Pfeilschifter J: Glucocorticoids protect renal mesangial cells from apoptosis by increasing cellular sphingosine-1-phosphate. Kidney Int 2010;77:870-879.

-26 Koch A, Völzke A, Wünsche C, Meyer Zu Heringdorf D, Huwiler A, Pfeilschifter J: Thiazolidinedione dependent activation of sphingosine kinase 1 causes an anti-fibrotic effect in renal mesangial cells. $\mathrm{Br} \mathrm{J}$ Pharmacol 2012;166:1018-1032.

27 Sanchez T, Hla T: Structural and functional characteristics of S1P receptors. J Cell Biochem 2004;92:913922. 
28 Meyer zu Heringdorf D, Lass H, Kuchar I, Lipinski M, Alemany R, Rümenapp U, Jakobs KH: Stimulation of intracellular sphingosine-1-phosphate production by G-protein-coupled sphingosine-1-phosphate receptors. Eur J Pharmacol 2001;414:145-154.

29 Katsuma S, Hada Y, Shiojima S, Hirasawa A, Tanoue A, Takagaki K, Ohgi T, Yano J, Tsujimoto G: Transcriptional profiling of gene expression patterns during sphingosine 1-phosphate-induced mesangial cell proliferation. Biochem Biophys Res Commun 2003;300:577-584.

- 30 Xin C, Ren S, Kleuser B, Shabahang S, Eberhardt W, Radeke H, Schäfer-Korting M, Pfeilschifter J, Huwiler A: Sphingosine 1-phosphate cross-activates the Smad signaling cascade and mimics transforming growth factor- $\beta$-induced cell responses. J Biol Chem 2004;279:35255-35262.

-31 Sauer B, Vogler R, von Wenckstern H, Fujii M, Azano MB, Glick AB, Schäfer-Korting M, Roberts AB, Kleuser B: Involvement of Smad signaling in sphingosine 1-phosphate-mediated biological responses of keratinocytes. J Biol Chem 2004;279:38471-38479.

-32 Radeke HH, von Wenckstern H, Stoidtner K, Sauer B, Hammer S, Kleuser B: Overlapping signaling pathways of sphingosine 1-phosphate and TGF-beta in the murine Langerhans cell line XS52. J Immunol 2005;174:27782786.

-33 Ren S, Babelova A, Moreth K, Xin C, Eberhardt W, Doller A, Pavenstädt H, Schaefer L, Pfeilschifter J, Huwiler A: Transforming growth factor- $\beta 2$ upregulates sphingosine kinase- 1 activity, which in turn attenuates the fibrotic response to TGF- $\beta 2$ by impeding CTGF expression. Kidney Int 2009; 76:857-867.

34 Xin C, Ren S, Eberhardt W, Pfeilschifter J, Huwiler A: The immunomodulator FTY720 and its phosphorylated derivative activate the Smad signaling cascade and upregulate connective tissue growth factor and collagen type IV expression in renal mesangial cells. Br J Pharmacol 2006;147:164-174.

-35 Ancellin N, Hla T: Differential pharmacological properties and signal transduction of the sphingosine 1-phosphate receptors EDG-1, EDG-3, and EDG-5. J Biol Chem 1999;274:18997-19002.

-36 Katsuma S, Ruike Y, Yano T, Kimura M, Hirasawa A, Tsujimoto G: Transcriptional regulation of connective tissue growth factor by sphingosine 1-phosphate in rat cultured mesangial cells. FEBS Lett 2005;579:25762582.

-37 Li MH, Sanchez T, Pappalardo A, Lynch KR, Hla T, Ferrer F: Induction of the anti-proliferative connective tissue growth factor expression in Wilms tumor cells by sphingosine 1-phosphate receptor 2. Mol Cancer Res 2008;6:1649-1656.

-38 Brinkmann V, Davies MD, Heise CE, Albert R, Cottens S, Hof R, Bruns C, Prieschl E, Baumruker T, Hiestand P, Foster CA, Zollinger M, Lynch KR: The immune modulator FTY720 targets sphingosine 1-phosphate receptors. J Biol Chem 2002;277:21453-21457.

39 Qiao L, Kozikowski AP, Olivera A, Spiegel S: Synthesis and evaluation of a photolyzable derivative of sphingosine 1-phosphate-caged SPP. Bioorg Med Chem Lett 1998;8:711-714.

40 Lan T, Liu W, Xie X, Xu S, Huang K, Peng J, Shen X, Liu P, Wang L, Xia P, Huang H: Sphingosine kinase-1 pathway mediates high glucose-induced fibroectin expression in glomerular mesangial cells. Mol Endocrinol 2011;25:2094-2105.

41 Venkatachalam MA, Bernard DB, Donohoe JF, Levinsky NG: Ischemic damage and repair in the rat proximal tubule: differences among the S1, S2 and S3 segments. Kidney Int 1978;14:31-49.

42 Lieberthal W, Nigam SK: Acute renal failure. I. Relative importance of proximal vs. distal tubular injury. Am J Physiol 1998;275:623-631.

43 Ryan MJ, Johnson G, Kirk J, Fuerstenberg SM, Zager RA, Torok-Storb B: HK-2: an immortalized proximal tubule epithelial cell line from normal adult human kidney. Kidney Int 1994;45:48-57.

44 Kim M, Kim M, Kim N, D’Agati VD, Emela CW Sr, Lee HT: Isoflurane mediates protection from renal ischemiareperfusion injury via sphingosine kinase and sphingosine-1-phosphate-dependent pathways. Am J Physiol Renal Physiol 2007;293:F1827-F1835.

45 Kim M, Kim M, Park SW, Pitson SM, Lee TH: Isoflurane protects human kidney proximal tubule cells against necrosis via sphingosine kinase and sphingosine-1-phosphate generation. Am J Nephrol 2009;31:353-362.

46 Lee HT, Kim M, Kim J, Kim N, Emala CW: TGF-beta1 release by volatile anesthetics mediates protection against renal proximal tubule cell necrosis. Am J Nephrol 2007;27:416-424.

-47 Song JH, Kim M, Park SW, Chen SWC, Pitson SM, Lee TH: Isoflurane via TGF- $\beta 1$ release increases caveolae formation and organizes sphingosine kinase signaling in renal proximal tubules. Am J Physiol Renal Physiol 2010;298:1041-1050. 
-48 Bajwa A, Jo SK, Ye H, Huang L, Dondeti KR, Rosin DL, Haase VH, Macdonald TL, Lynch KR,Okusa MD: Activation of sphingosine-1-phosphate 1 receptor in the proximal tubule protects against ischemia-reperfusion injury. J Am Soc Nephrol 2010;21:955-965.

49 Park WS, Kim M, Kim M, D’Agati VD, Lee HT: Sphingosine kinase 1 protects against renal ischemia-reperfusion injury in mice by sphingosine1-1phosphate1 receptor activation. Kidney Int 2011;80:1315-1327.

50 Park WS, Kim M, Brown KM, D’Agati VD, Lee HT: Inhibition of sphingosine 1-phosphate receptor 2 protects against renal ischemia-reperfusion injury. J Am Soc Nephrol 2012;23:266-280.

51 Bischoff A, Czyborra P, Fetscher C, Meyer zu Heringdorf D, Jakobs KH, Michel MC: Sphingosine-1-phosphate and sphingosylphosphorylcholine constricts renal and mesenteric microvessels in vitro. Br J Pharmacol 2000;130:1871-1877.

52 Bischoff A, Czyborra P, Meyer zu Heringdorf D, Jakobs KH, Michel MC: Sphingosine-1-phosphate reduces rat renal and mesenteric blood flow in vivo in a pertussis toxin-sensitive manner. Br J Pharmacol 2000;130:18781883.

53 Bischoff A, Meyer zu Heringdorf D, Jakobs KH, Michel MC: Lysosphingolipid receptor-mediated diuresis and natriuresis in anaesthetized rats. Br J Pharmacol 2001;132:1925-1933.

54 Jackson EK: Role of sphingosine-1-phosphate in the renal medulla. Am J Physiol Renal Physiol 2011;301:3334.

55 Zhu Q Xia M, Wang Z, Li PL, Li N: A novel lipid natriuretic factor in the renal medulla: sphingosine-1phosphate. Am J Physiol Renal Physiol 2011;301:F35-F41.

56 Visentin B, Vekich JA, Sibbald BJ, Cavalli AL, Moreno KM, Matteo RG, Garland WA, Lu Y, Yu S, Hall HS, Kundra V, Mills GB, Sabbadini RA: Validation of an anti-sphingosine-1-phosphate antibody as a potential therapeutic in reducing growth, invasion, and angiogenesis in multiple tumor lineages. Cancer Cell 2006;9:225-238.

57 O'Brien N, Jones ST, Williams DG, Cunningham HB, Moreno K, Visentin B, Gentile A, Vekich J, Shestowsky W, Hiraiwa M, Matteo R, Cavalli A, Grotjahn D, Grant M, Hansen G, Campbell MA, Sabbadini R: Production and characterization of monoclonal anti-sphingosine-1-phosphate antibodies. J Lipid Res 2009;50:2245-2257.

-58 Caballero S, Swaney J, Moreno K, Afzal A, Kielczewski J, Stoller G, Cavalli A, Garland W, Hansen G, Sabbadini R, Grant MB: Anti-sphingosine-1-phosphate monoclonal antibodies inhibit angiogenesis and sub-retinal fibrosis in a murine model of laser-induced choroidal neovascularization. Exp Eye Res 2009;88:367-377.

59 Huwiler A, Bourquin F, Kotelevets N, Pastukhov O, Capitani G, Grütter MG, Zangemeister-Wittke U: A prokaryotic S1P lyase degrades extracellular S1P in vitro and in vivo: implication for targeting hyperproliferative disorders. PLoS One 2011;6:e22436.

60 Schena FP, Gesualdo L: Pathogenetic mechanisms of diabetic nephropathy.J Am Soc Nephrol 2005;16:S30-S33.

61 Breyer MD, Böttinger E, Brosius III FC, Coffman TM, Harris RC, Heilig CW, Sharma K: Mouse models of diabetic nephropathy. J Am Soc Nephrol 2005;16:27-45.

62 Geoffroy K, Troncy L, Wiernsperger N, Lagarde M, El Bawab S: Glomerular proliferation during early stages of diabetic nephropathy is associated with local increase of sphingosine-1-phosphate levels. FEBS Lett 2005;579:1249-1254.

-63 Lan T, Shen X, Liu P, Liu W, Xu S, Xie X, Jiang Q, Li W, Huang H: Berberine ameliorates renal injury in diabetic C57BL/6 mice: involvement of suppression of Sphk-S1P signaling pathway. Arch Biochem Biophys 2010;502:112-120.

64 Imasawa T, Kitamura H, Ohkawa R, Satoh Y, Miyashita A, Yatomi Y: Unbalanced expression of sphingosine 1-phosphate receptors in diabetic nephropathy. Exp Toxicol Pathol 2010;62:53-60.

65 Awad AS, Rouse MD, Khutsishvili K, Huang L, Bolton WK, Lynch KR, Okusa MD: Chronic sphingosine 1-phosphate receptor activation attenuates early-stage diabetic nephropathy independent of lymphocytes. Kidney Int 2011;79:1090-1098.

66 Seymour AE: Glomerulonephritis: approaches to classification. Pathology 1985;17:225-238.

67 Peters H, Martini S, Wang Y, Shimizu F, Kawachi H, Krämer S, Neumayer HH: Selective lymphocyte inhibition by FTY720 slows the progressive course of chronic anti-thy 1 glomerulosclerosis. Kidney Int 2004;66:14341443.

68 Martini S, Krämer S, Loof T, Wang-Rosenke Y, Daig U, Budde K, Neumayer HH, Peters H: S1P modulator FTY720 limits matrix expansion in acute anti-thy 1 mesangioproliferative glomerulonephritis. Am J Physiol Renal Physiol 2007;292:F1761-F1770. 
69 Lebleu VS, Sugimoto H, Miller CA, Gattone VH 2nd, Kalluri R: Lymphocytes are dispensable for glomerulonephritis but required for renal interstitial fibrosis in matrix defect-induced Alport renal disease. Lab Invest 2008;88:284-292.

70 Sui M, Zhou J, Xie R, Liu X, Mu S, Jia X, Ma J, Wu H: The sphingosine-1-phosphate receptor agonist FTY720 prevents the development of anti-glomerular basement membrane glomerulonephritis. Mol Biol Rep 2011;39:389-397.

71 Wenderfer SE, Stepkowski SM, Braun MC: Increased survival and reduced renal injury in MRL/lpr mice treated with a novel sphingosine-1-phosphate receptor agonist. Kidney Int 2008;74:1319-1326.

72 Shimizu H, Takahashi M, Kaneko T, Murakami T, Hakamata Y, Kudou S, Kishi T, Fukuchi K, Iwanami S, Kuriyama K, Yasue T, Enosawa S, Matsumoto K, Takeyoshi I, Morishita Y, Kobayashi E: KRP-203, a novel synthetic immunosuppressant, prolongs graft survival and attenuates chronic rejection in rat skin and heart allografts. Circulation 2005;111:222-229.

73 Cohen PL, Eisenberg RA: Lpr and gld: single gene models of systemic autoimmunity and lympho-proliferative diseases. Annu Rev Immunol 1991;9:243-269.

74 Chatauret N, Thuillier R, Hauet T: Preservation strategies to reduce ischemic injury in kidney transplantation: pharmacological and genetic approaches. Curr Opin Organ Transplant 2011;16:180-187.

75 Zager RA, Iwata M, Conrad DS, Burkhart KM, Igarashi Y: Altered ceramide and sphingosine expression during the induction phase of ischemic acute renal failure. Kidney Int 1997;52:60-70.

76 Kalhorn T, Zager RA: Renal cortical ceramide patterns during ischemic and toxic injury: assessments by HPLC-mass spectrometry. Am J Physiol 1999;277:F723-733.

77 Zager RA, Conrad DS, Burkhart K: Ceramide accumulation during oxidant renal tubular injury: mechanisms and potential consequences. J Am Soc Nephrol 1998;9:1670-1680.

78 Jo SK, Bajwa A, Ye H, Vergis AL, Awad AS, Kharel Y, Lynch KR, Okusa MD: Divergent roles of sphingosine kinases in kidney ischemia-reperfusion injury. Kidney Int 2009;75:167-175.

79 Jin ZQ, Zhang J, Huang Y, Hoover HE, Vessey DA, Karliner JS: A sphingosine kinase 1 mutation sensitizes the myocardium to ischemia/reperfusion injury. Cardiovasc Res 2007;76:41-50.

80 Vessey DA, Li L, Jin ZQ, Kelley M, Honbo N, Zhang J, Karliner JS: A sphingosine kinase form 2 knockout sensitizes mouse myocardium to ischemia/reoxygenation injury and diminishes responsiveness to ischemic preconditioning. Oxid Med Cell Longev 2011;2011:961059.

-81 Troncoso P, Ortíz M, Martínez L, Kahan BD: FTY 720 prevents ischemic reperfusion damage in rat kidneys. Transplant Proc 2001;33:857-859.

-82 Awad AS, Ye H, Huang L, Li L, Foss FW Jr, Macdonald TL, Lynch KR, Okusa MD: Selective sphingosine 1-phosphate 1 receptor activation reduces ischemia-reperfusion injury in mouse kidney. Am J Physiol Renal Physiol 2006;290:F1516-F1524.

83 Lien YH, Yong KC, Cho C, Igarashi S, Lai LW: S1P(1)-selective agonist, SEW2871, ameliorates ischemic acute renal failure. Kidney Int 2006;69:1601-1608.

84 Lai LW, Yong KC, Igarashi S, Lien YH: A sphingosine-1-phsophate type 1 receptor agonist inhibits the early T-cell transient following renal ischemia-reperfusion injury. Kidney Int 2007;71:1223-1231.

-85 Ysebaert DK, De Greef KE, De Beuf A, Van Rompay AR, Vercauteren S, Persy VP, De Broe ME: T cells as mediators in renal ischemia/reperfusion injury. Kidney Int 2004;66:491-496.

-86 Lee SY, Kim DH, Sung SA, Kim MG, Cho WY, Kim HK, Jo SK: Sphingosine-1-phosphate reduces hepatic ischemia/reperfusion-induced acute kidney injury through attenuation of endothelial injury in mice. Nephrology 2011;16:163-173.

-87 Sola A, Weigert A, Jung M, Vinuesa E, Brecht K, Weis N, Brüne B, Borregaard N, Hotter G: Sphingosine-1phosphate signalling induces the production of Lcn-2 by macrophages to promote kidney regeneration. J Pathol 2011;225:597-608.

-88 Varan A: Wilms' tumor in children: an overview. Nephron Clin Pract 2008;108:83-90.

89 Pyne NJ, Pyne S: Sphingosine 1-phosphate and cancer. Nat Rev Cancer 2010;10:489-503.

-90 Zirn B, Hartmann O, Samans B, Krause M, Wittmann S, Mertens F, Graf N, Eilers M, Gessler M: Expression profiling of Wilms tumors reveals new candidate genes for different clinical parameters. Int J Cancer 2006;118:1954-1962.

91 Simoni D, Tolomeo M: Retinoids, apoptosis and cancer. Curr Pharm Des 2001;7:1823-1837. 
-92 Zirn B, Samans B, Spangenberg C, Graf N, Eilers M, Gessler M: All-trans retinoic acid treatment of Wilms tumor cells reverses expression of genes associated with high risk and relapse in vivo. Oncogene 2005;24:52465251.

$\$ 93$ Jacobson A, Cunningham JL: Connective tissue growth factor in tumor pathogenesis. Fibrogenesis Tissue Repair 2012;5:S8.

$\$ 94$ Li MH, Sanchez T, Pappalardo A, Lynch KR, Hla T, Ferrer F: Induction of antiproliferative connective tissue growth factor expression in Wilms' tumor cells by sphingosine-1-phosphate receptor 2. Mol Cancer Res 2008;6:1649-1656.

95 Li MH, Sanchez T, Yamase H, Hla T, Oo ML, Pappalardo A, Lynch KR, Lin CY, Ferrer F: S1P/S1P1 signaling stimulates cell migration and invasion in Wilms tumor. Cancer Lett 2009;276:171-179.

-96 Li MH, Sanchez T, Milne GL, Morrow JD, Hla T, Ferrer F: S1P/S1P 2 signaling induces cyclooxygenase-2 expression in Wilms tumor. J Urol 2009;181:1347-1352.

-97 Khan Z, Khan N, Tiwari RP, Sah NK, Prasad GB, Bisen PS: Biology of Cox-2: an application in cancer therapeutics. Curr Drug Targtes 2011;12:1082-1093.

-98 Lee A, Frischer J, Serur A, Huang J, Bae JO, Kornfield ZN, Eljuga L, Shawber CJ, Feirt N, Mansukhani M, Stempak D, Baruchel S, Bender JG, Kandel JJ, Yamashiro DJ: Inhibition of cyclooxygenase-2 disrupts tumor vascular mural cell recruitment and survival signaling. Cancer Res 2006;66:4378-4384. 